\title{
One-Staged Subtotal Sacrectomy for Primary Sacral Tumor
}

\author{
Chucheep Sahakitrungruang, MD, MSc ${ }^{1}$ and Kraisri Chantra, $\mathrm{MD}^{2}$ \\ ${ }^{1}$ Colorectal Surgery Division, Department of Surgery, Chulalongkorn University, Bangkok, Thailand; ${ }^{2}$ Neurological \\ Surgery Division, Department of Surgery, Chulalongkorn University, Bangkok, Thailand
}

\begin{abstract}
Background. Sacrectomy with adequate margins is challenging because of the complexity of the surgical approach and morbidities. Two-staged sequential approach, therefore, has been advocated. This study was designed to demonstrate the modification of this technique.

Methods. This is a case presentation of a 45-year-old man with chordoma involving the lower border of S2, who underwent one-staged subtotal sacrectomy. The technique involved the following: midline incision, mobilization of the rectum, construction of a colostomy and the modified Hartmann stump with intact superior rectal vessels, ligation of internal iliac arteries, ligation of all branches connecting to external iliac veins resulting in "complete isolation" of the external iliac veins, dissection of presacral tissue, anterior osteotomy at the S1-S2 junction and the sacroiliac joints, and abdominal closure. The posterior approach involved a threelimbed incision, dissection of the gluteus muscle and ligaments from the sacrum, subperiosteal dissection, S1 laminectomy, posterior osteotomy corresponding with the anterior osteotomy line with preservation of S1 nerves, division of S2-S4 nerves from sciatic nerves, and specimen removal. Closure of the large sacral defect was undertaken using the Hartmann stump and bilateral gluteus maximus flaps.

Results. En bloc resection with free margins without tumor rupture was accomplished. Operative time was
\end{abstract}

Electronic supplementary material The online version of this article (doi:10.1245/s10434-009-0570-x) contains supplementary material, which is available to authorized users.

(C) Society of Surgical Oncology 2009

First Received: 4 December 2008;

Published Online: 30 June 2009

C. Sahakitrungruang, MD, MSc

e-mail: chucheep@hotmail.com
12 hours. Blood transfusion was 6 units. This patient had a good recovery without complications. He was able to ambulate within 1 week and walk normally within 1 month. No recurrence was found at a 24-month-followup.

Conclusions. One-staged sacrectomy can be safely performed, obtaining the satisfactory outcomes.

\section{REFERENCES}

1. Wuisman P, Lieshout O, Sugihara S, van Dijk M. Total sacrectomy and reconstruction: oncologic and functional outcome. Clin Orthop Relat Res. 2000:192-203.

2. Fourney DR, Rhines LD, Hentschel SJ, Skibber JM, Wolinsky JP, Weber KL, et al. En bloc resection of primary sacral tumors: classification of surgical approaches and outcome. J Neurosurg Spine. 2005;3:111-22.

3. Gallia GL, Haque R, Garonzik I, Witham TF, Khavkin YA, Wolinsky JP, et al. Spinal pelvic reconstruction after total sacrectomy for en bloc resection of a giant sacral chordoma. Technical note. J Neurosurg Spine. 2005;3:501-6.

4. Diaz J, McDonald WS, Armstrong M, Eismont F, Hellinger M, Thaller S. Reconstruction after extirpation of sacral malignancies. Ann Plast Surg. 2003;51:126-9.

5. Miles WK, Chang DW, Kroll SS, Miller MJ, Langstein HN, Reece GP, et al. Reconstruction of large sacral defects following total sacrectomy. Plast Reconstr Surg. 2000;105:2387-94. 